\title{
Knowledge and Awareness of Cervical Cancer, Human Papillomavirus (HPV), and HPV Vaccine among Screening Women: A Cross-Sectional Study from a Tertiary Care Hospital in South India
}

\author{
Priya Arumugam ${ }^{1}$, Syed Habeebullah ${ }^{2}$ and Subhash Chandra Parija ${ }^{1^{*}}$ \\ ${ }^{1}$ Department of Microbiology, Jawaharlal Institute of Postgraduate Medical Education and \\ Research, JIPMER, Puducherry, India \\ ${ }^{2}$ Department of Obstetrics and Gynaecology, Jawaharlal Institute of Postgraduate Medical \\ Education and Research, JIPMER, Puducherry, India \\ *Corresponding author
}

\section{A B S T R A C T}

Even though cervical cancer is quite a common cancer in India, there are limited studies on the knowledge and awareness about the disease. It is important to assess the knowledge

Keywords

Cervical cancer, Human

Papillomavirus (HPV)

Article Info

Accepted:

20 February 2018

Available Online:

10 March 2018 among the screening populations have about cervical cancer and Human papillomavirus (HPV) and their attitudes toward HPV vaccination, as it will directly influence their decision-making for the acceptability of healthcare programs. Public education and awareness about HPV infection, HPV vaccination programs are pertinent for a successful cervical cancer screening program available in the country. Our present study was designed to assess the level of knowledge and awareness about cervical cancer, HPV, and the HPV vaccine among screening women in tertiary care hospital, Puducherry. Qualitative data were collected from screening population through in-depth interviews in the Gynecological Outpatient Department at JIPMER, a tertiary care hospital in India during July 2013 - Aug 2014. A total of 152 women were recruited and asked to participate in a questionnaire-based interview that collected qualitative data about their awareness and knowledge about: (1) cervical cancer, (2) Human papillomavirus and (3) HPV vaccine. The study was approved by the institutional ethics committee. Written informed consent was taken from the women who were enrolled in this study.

\section{Introduction}

Cervical cancer remains the most common cancer in women worldwide. Globally cervical cancer contributes to $12 \%$ of all types of cancer after breast cancer. Low and middle income countries (LMICs) contribute to $85 \%$ cervical cancer cases (Globocan, 2012 and Bruni et al., 2014). Developed countries reduced the cervical cancer incidence and mortality rates because of the wide application of cervical screening tests and vaccinations (Haesebaert et al., 2012 and Giles 2006). To lower the cervical cancer incidence, early detection is the only way to reduce morbidity and mortality. To implement any cervical cancer screening program and for its successful functioning, 
awareness about the disease, causative agent of the disease, the available vaccines for the prevention of the disease should be known by the target population group.

Knowledge about cervical cancer merely exists among Indian women with some women from rural areas describing the early symptoms of cervical cancer such as bleeding as the recurrence of the menstrual cycle (Charity Binka et al., 2017). This poor understanding about the menstrual practice along with the misconceptions and unawareness of what cervical cancer is, leads to the avoidance and poor health seeking behaviors.

From the documented literature, accurate knowledge about cervical cancer, HPV virus, HPV vaccination tends to be low in developing countries in comparison to developed countries, worldwide (Wong et al., 2009, Songthap et al., 2009 and Marlow et al., 2013). Several studies have been reported about the knowledge, attitude and practice (KAP) on cervical cancer, Human papillomavirus (HPV), and HPV vaccination from other parts of North India. South India lacks studies on knowledge, attitude and practice (KAP) and documented research data are scarce, the few documented studies are from Bangalore, Mangalore, and Kerala (Swapnajaswanth et al., 2014, Canon et al., 2017 and Aswathy et al., 2012). Therefore, it is important to conduct studies to improve the knowledge, attitudes and perceptions of cervical cancer among women. The aim of the present study was sought to evaluate the baseline information about the knowledge and awareness of women on cervical cancer, HPV and HPV vaccination.

\section{Materials and Methods}

A descriptive questionnaire based study was conducted to collect qualitative data from randomly selected 152 women who was visited Gynecology Out-Patient Department of Tertiary care hospital, JIPMER for their routine screening during 2013 -2014. The study was approved by the Institute Ethics Committee. All the participants of the survey were explained about this study prior to their participation and approval was taken in a written informed consent.

The questionnaire was covered to get the details about the demographic details, sexual life data, educational and occupational details. The survey included an open-ended question such as "Have you heard of cervical cancer, Human papillomavirus, and HPV vaccination?" Data was collected by using structured questionnaire by interviewing the participant to find out knowledge and practice and Data was analyzed by using MEDCALC ${ }^{\circledR}$ online statistical software.

\section{Results and Discussion}

A total of 152 screening women were included; 103/152 (67.7\%) were from rural area, and 49/152 (32.2\%) were from urban area. Overall, 121/152 (79.6\%) of the women were aware of cervical cancer, with not much significant difference between rural and urban women. Overall, 5\% of the women were aware of the role of HPV in cervical cancer. The knowledge that HPV infection leads to cervical cancer was higher among urban women compared to women of rural background. Knowledge about the HPV vaccine was very poor in all women regardless of their demographic location, occupation and educational status.

This study was carried out to elicit information on the knowledge and awareness regarding cervical cancer, HPV and HPV among screening women population. Though the level of awareness and knowledge about cervical cancer was moderate, knowledge and 
awareness of HPV and the HPV vaccine was very poor. Despite being known for the extreme efficacy of the cervical cancer screening, larger proportion of women who do not avail themselves the benefits of the screening programs due to the lack of knowledge and awareness. Knowledge gaps exist in the targeted population and they are unaware of the HPV or the vaccination program which is available to prevent the cervical cancer.

Adequate knowledge and awareness of cervical cancer and HPV and positive attitude about HPV vaccination are essential prerequisites for healthcare professionals to provide screening programs. Willingness for the uptake of HPV vaccines should be a priority in developing countries since they contribute to 88 per cent of global cervical cancer burden (Madhivanan et al., 2014). Lack of awareness about the cause of the cancer, risk factors and symptoms of the cervical cancer were reported from the participants from our demographic region. Adequate support to voluntary organizations/ non-governmental organizations working in health sector for increasing awareness on cervical cancer among both healthcare providers and the general public could further help in reducing the burden of this disease. Therefore, educational strategies that highlight the consequences of HPV could promote acceptance of cervical cancer screening. Our study findings reinforce continued medical education of healthcare providers, particularly those from the government sector on HPV vaccination for cervical cancer prevention.

In conclusion, most of the women participated in our study have inadequate knowledge and awareness regarding cervical cancer screening. Hence there is a stand in need to promote the uptake of the cervical cancer prevention and screening programs by health professionals. Health camps and awareness program should be conducted at community level for women to increase the level of knowledge and practice regarding cervical cancer screening.

\section{Conflict of interest}

Authors declare no conflict of interest

\section{Acknowledgment}

This study was financially supported by Jawaharlal Institute of Post Graduate Medical Education and Research (JIPMER), Puducherry. We thank all the women who agreed to participate in this study. We acknowledge the consultants and resident doctors of Obstetrics and Gynecology department for their help and support in recruiting the participants.

\section{References}

Aswathy S, Quereshi MA, Kurian B, Leelamoni K (2012). Cervical cancer screening: Current knowledge \& practice among women in a rural population of Kerala, India. Indian $\mathbf{J}$ Med Res, 136:205-10.

Binka C, Doku DT, Awusabo-Asare K (2017). Experiences of cervical cancer patients in rural Ghana: An exploratory study. PLoS ONE 12 (10): e0185829. https://doi.org/10.1371/journal. pone.0185829

Bruni L, Barrionuevo-Rosas L, Albero G AM (2015). Human papillomavirus and related diseases in Asia. Summary report.

Canon, C., Effoe, V., Shetty, V. J Canc Educ (2017) 32: 382. https://doi.org/10. 1007/s13187-016-0999-0.

Giles M, Garland S, (2006): A study of women's knowledge regarding human papillomavirus infection, cervical 
cancer and human papillomavirus vaccines. Aust NZJ Obstet Gynaecol, 46: 311-15

Globocan (2012). Estimated cancer incidence, mortality and prevalence worldwide in 2012. Available at: http://globocan. iarc.fr/Default.aspx, accessed 25 May 14.

Haesebaert J, Luntringer-Magnin D, Kalecinski J (2012): French women's knowledge of and attitudes toward cervical cancer prevention and the acceptability of HPV vaccination among those with 14-18 year old daughters: A quantitative-qualitative study. BMC Public Health, 12, 1034-44.

Madhivanan P, Srinivas V, Marlow L, Mukherjee S, Narayanappa D, Mysore $S$ (2014). Indian parents prefer vaccinating their daughters against HPV at older ages. Asian Pac J Cancer Prev, 15:107-10.

Marlow LA, Zimet GD, McCaffery KJ, Ostini R, Waller J (2013). Knowledge of human papillomavirus (HPV) and HPV vaccination: an international comparison. Vaccine, 31:763-9.

Songthap A, Pitisuttithum P, Kaewkungwal J, Fungladda W, Bussaratid V, Koonsaeng S (2009).. Knowledge, attitudes, and acceptability of a human papillomavirus vaccine among healthcare providers. Southeast Asian J Trop Med Public Health, 40:1048-56.

Swapnajaswanth M, Suman G, Suryanarayana SP, Murthy NS (2014). Perception and practices on screening and vaccination for carcinoma cervix among female healthcare professional in tertiary care hospitals in Bangalore, India. Asian Pac J Cancer Prev, 15, 6095-8.

Wong LP, Wong YL, Low WY, Khoo EM, Shuib R (2009). Knowledge and awareness of cervical cancer and screening among Malaysian women who have never had a Pap smear: a qualitative study. Singapore Med J, 50:49-53.

\section{How to cite this article:}

Priya Arumugam, Syed Habeebullah and Subhash Chandra Parija. 2018. Knowledge and Awareness of Cervical Cancer, Human Papillomavirus (HPV), and HPV Vaccine among Screening Women: A Cross-Sectional Study from a Tertiary Care Hospital in South India. Int.J.Curr.Microbiol.App.Sci. 7(03): 2431-2434. doi: https://doi.org/10.20546/ijcmas.2018.703.283 